\title{
A DESCENTRALIZAÇÃO DO ESTADO DE SANTA CATARINA (BRASIL) E O ASSOCIATIVISMO INTER- MUNICIPAL
}

\author{
Maria Helena NICOLLI
}

\section{INTRODUÇÃO.}

O artigo científico é uma reflexão sobre a efetividade da descentralização do governo catarinense, frente ao desempenho do associativismo intermunicipal em áreas microrregionalizadas no Estado de Santa Catarina (Brasil). Os municípios constituem o locus privilegiado para os serviços públicos e a concretização do desenvolvimento sustentável e integrado através do associativismo intermunicipal em toda a área do Estado Catarinense, constituído historicamente desde a década de 70. Porém, a partir de (2003), o governo catarinense optou pela descentralização governamental, implantando áreas microrregionalizadas, que se sobrepõe às áreas do associativismo intermunicipal para o seu processo descentralizado. Estimulando as tendências da participação organizada dos vários segmentos da sociedade nas questões das políticas públicas e descentralização de poder.

A descentralização, posicionamento teórico e prático do governo Estadual, implantada em áreas microrregionalizadas paralelas as do associativismo intermunicipal difunde-se com a práxis do governo local e articula-se em alguns momentos, porém, sem uma efetivação concreta com as ações do associativismo intermunicipal. Esse procedimento justifica-se por ambos possuírem objetivos diferenciados em seus planos governamentais para o desenvolvimento local, com integração de ações públicas e privadas e os desafios relativos à expansão da cidadania e da inclusão social.

Nesse contexto, as municipalidades e os cidadãos conforme a idéia de (CAVAlCANTI, 2003, p.9) "devem ser o alfa e o ômega de todas as ações da administração pública”. A preocupação com o desenvolvimento estrutural principalmente o social reflete a exigência da "efetividade." das políticas públicas, juntamente com os conceitos de eficácia e eficiência do governo estadual e local. Com visões futuras, para além das formas de atuação ou escolhas políticas

\footnotetext{
${ }^{1}$ Cavalcanti, B. S. 2002. In: Vergara, S. C. \& CorrêA, V. L. A . (orgs.), 2003. Propostas para uma gestão pública municipal efetiva. Rio de Janeiro: Fundação Getúlio Vargas.
} 
(descentralização e associativismo), mas também, sobre o que fazer e das racionalidades como fazer.

Para (MelLo, 1991), “[...] um dos maiores desafios para a efetivação da descentralização consiste na atribuição aos governos locais de recursos financeiros que lhes permitam cumprir um papel efetivo no processo de desenvolvimento, capacitando-os financeiramente para a prestação de serviços sob sua responsabilidade" .

Nestes dois processos, em que, o orçamento é responsabilidade de cada instituição, onde o estado financia algumas obras em área microrregionalizadas, por iniciativa da descentralização ou por reivindicação dos governos locais. O que mais põem em questionamento é de que forma a descentralização tem poder de efetividade diante da falta de uma integração consistente.

\section{O HISTÓRICO DA DESCENTRALIZAÇÃO NO BRASIL.}

A história do Brasil é de centralização político e administrativa. No período de Colônia (1500-1822), a independência veio muito mais pela vontade das elites descontentes com a metrópole, do que da vontade do conjunto da população. No período Imperial (1822-1889), a situação não muda em relação ao envolvimento da população com as questões políticas. Nem mesmo no o advento da República (1889), ocorreu devido a pressões de uma população em luta por melhores condições de vida e sim, pelo descontentamento dos militares com o espaço que ocupavam na vida política. A participação popular só irá se alterar a partir da década (1920) e culminará na revolução de (1930), com o final da Primeira República e propiciando a Segunda República que irá até (1964), quando há um golpe militar que somente se encerrará, de fato, com o processo constituinte e a promulgação da Constituição de 1988.

Para (MeLo,1990) a partir da década de (1970) o Brasil ressurge em pleno "milagre econômico", com elevadas taxas de crescimento, com amplas perspectivas para o desenvolvimento.

Nesse período da-se inicio as burocracias públicas ao impulso da industrialização, urbanização, à formação de grandes monopólios. E a partir de então foram implantados binômios de igualdade de resultado, de oportunidades, distri-

\footnotetext{
${ }^{2}$ Mello, Diogo Lordello de. (1991) «Descentralização, Papel dos Governos Locais no Processo de Desenvolvimento Nacional e Recursos Financeiros necessários para que os governos Locais Passam Cumprir seu Papel», Revista da Administração Pública, vol. 25,n. ${ }^{\circ}$ 4,outubro/dezembro 1991.

${ }^{3}$ Melo, Marcus André B.C. de (1990) «A formação de Políticas Públicas e a Transmissão Democrática: O Caso da Política Social». Dados, vol.33,n. ${ }^{\circ} 3$ pp. 443-470.
} 
buição de direitos, universalismo, particularismo, clientelismo, corporativismo, graus de segurança e insegurança social. "[...] uma acelerada montagem das estruturas centralizadas do aparelho econômico é a definição da nova forma do Estado." (DRAIBE, 1989:276) ${ }^{4}$.

Desse modo, tomava fôlego de forma crescente, no cenário político, econômico e social a idéia de que as novas tecnologias possibilitariam uma reconstituição das relações de trabalho e dos sistemas de produção em bases sociais, econômicas e geográficas inteiramente diferenciadas dos períodos anteriores. Também a mobilização da sociedade civil via o sindicalismo e os movimentos de bases e um outro elemento aponta para a modernização conservadora a terceirização dos serviços e o aumento de estudantes universitários.

A partir de 1990 o Brasil, começa um momento de transição do modelo desenvolvimento do Estado para um de reformas do corte neoliberal, quando este começa a ceder espaço para o mercado. O poder público vivencia um momento de transformações provocada em grande parte pela globalização da economia e pelo avanço tecnológico passam a agir no mesmo espaço de modo a permitir uma maior potencialização de energias voltadas ao desenvolvimento local. Marca a emergência de novos paradigmas centrados de uma gestão democrática e participativa, descentralizada, na qual o poder local o processo de desenvolvimento do país.

Também, na última década, a sociedade aponta progressivamente para a emergência de um novo poder. Este por sua vez não estaria mais sob submissão; do partido, do mercado e nem do Estado. Atualmente tal poder tende a ser reconstituído e solidificado no próprio cerne da sociedade organizada.

\section{A EFETIVIDADE DA DESCENTRALIZAÇÃO DO ESTADO CATARINENSE E O ASSOCIATIVISMO INTERMUNICIPAL.}

Progressivamente, a partir dos anos 70, estão surgindo debates contemporâneos sobre questões que contemplam a descentralização do Estado como resposta à crise do bem-estar. Desta maneira destacam-se temas pertinentes à redefinição dos novos paradigmas para as esferas governamentais e seus níveis de intervenção. Cada vez mais os Estados e Municípios brasileiros, tem sofrido pressões através da sociedade organizada, na busca por melhores resultados. Ambos tem lançado mão de instrumentos como o planejamento participativo onde expressam objetivos e metas desejados pelos contribuintes. Isso marca a emergência de novos paradigmas, centrados principalmente em uma gestão de-

\footnotetext{
${ }^{4}$ Draibe, Sônia Mirian. Rumos e Metamorfoses. Rio de Janeiro, Paz e Terra. 1985.
} 
mocrática e participativa, descentralizada, flexível e autônoma na qual o poder local assume, de modo inédito, a dianteira do desenvolvimento.

A partir da década de 90, o poder público vivencia, uma profunda redefinição do papel do Estado, uma agenda de reformas e inspirações neoliberal, que aponta para novas formas de resolução, baseada na idéia do Estado mínimo.

\subsection{Razões do processo de descentralização do Estado Catarinense.}

O governo catarinense a partir de 2003, inicia na prática a reforma administrativa com o processo de desconcentração e descentralização fundamentado na Lei Complementar n. ${ }^{\circ}$ 284, de fevereiro de 2005, que estabelece modelo de gestão para a Administração Pública Estadual e dispõe sobre a estrutura organizacional do poder Executivo. Propõe uma reengenharia governamental para a redistribuição de funções. Substituindo funções centralizadas por regionalizadas. Essa regionalização consta na implantação de 30 Secretarias de Desenvolvimento Regional com seus respectivos Conselhos Regionais, distribuídos em áreas microrregionais, diferenciadas das microrregiões estabelecidas pelo associativismo intermunicipal.

A atuação destas agências oficiais do governo estadual objetiva o desenvolvimento sustentável. E tem dois aspectos distintos e complementares. De um lado, funcionam como extensão do governo, e de outro, atuam como verdadeiras Agências de Desenvolvimento Regional, com orçamento regionalizado e participativo, quando aprovado pelo governador, com planejamento para o desenvolvimento de médio e longo prazo, com detalhamento microrregional.

A estrutura da descentralização ainda se complementa com os Conselhos Regionais, também em número de 30, (integrados pelos prefeitos e representante de órgãos comunitários), representam a força de cada região e os "Fóruns Permanentes de Debates" tratam sobre a aplicação do orçamento regionalizado, objetivando atender a escala de prioridades e ações, conta com a integração do estado, dos municípios, universidades e representantes comunitários para discutir o planejamento e execução das metas. A proposta do plano governamental visa a democratização, transparência, engajamento, planejamento, fiscalização das ações com objetivo ao desenvolvimento econômico-social.

Segundo o vice-governado do Estado de Santa Eduardo Pinho Moreira em mensagem escrita a população declara que:

O Estado moderno tem que ser menos demiurgo e mais inteligente, menos auto-suficiente e mais parceiro da sociedade. Para isso, tem que se tornar um Estado do saber e da competência, comprometido com a inovação, com as novas tecnologias de informação e comunicação pois cada dia mais a gestão racional 
dos recursos deixa de ser um luxo e passa a ser condição vital para o desenvolvimento ( PINHO, 2003) 5 .

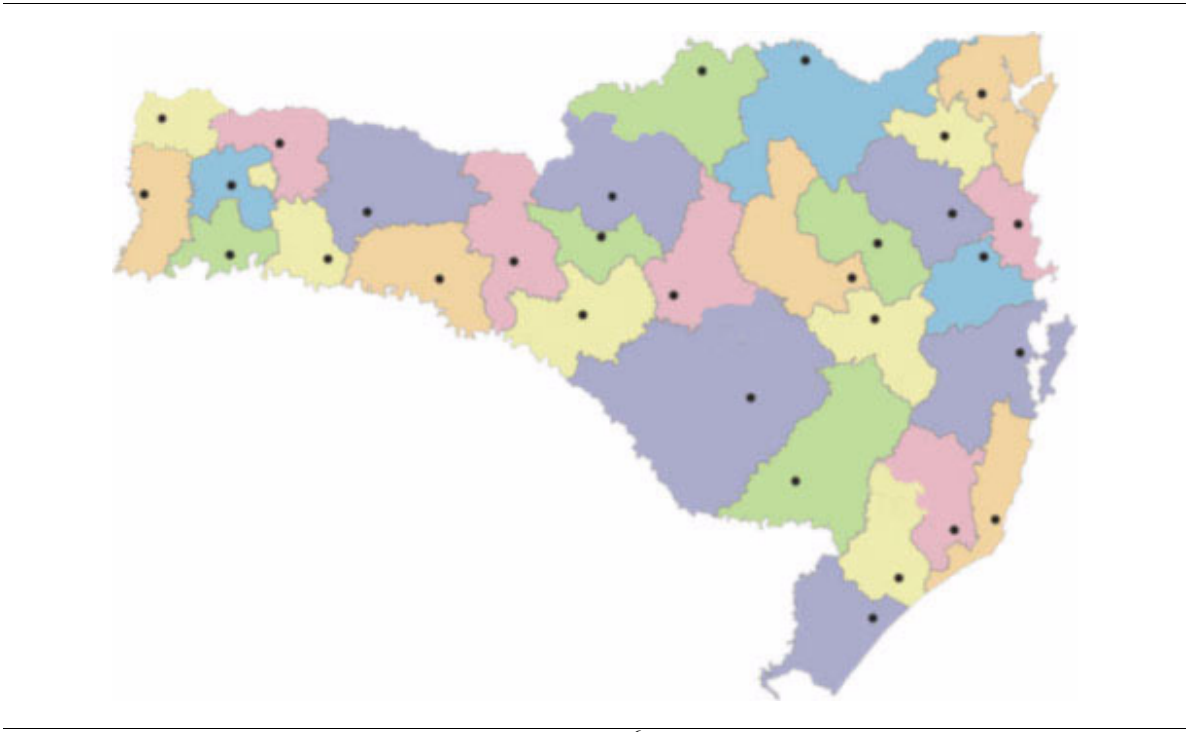

Fig. $1^{6}$

O estado no processo de descentralização se apresenta com um planejamento que possibilita um modelo praticamente informatizado, acreditando ser esta uma verdadeira revolução na forma de governar em regime democrático e desta forma garantiria a participação da sociedade e das comunidades.

Porém, na institucionalização do processo administrativo descentralizado e desconcentrado, encontra-se diante de duas situações; a microrregionalização estabelecida pelo estado para a descentralização e a estrutura microrregionalizada instituída pelo associativismo intermunicipal. Frente a estas duas situações, questionamos como acontece a efetividade ? Se, em cada uma das situações possui um planejamento específico (governo estadual), com objetivos voltados a descentralização e o associativismo intermunicipal (associações dos go-

\footnotetext{
${ }^{5}$ PINHO, Moreira, Eduardo, Vice- Governador do Estado de Santa Catarina, (Manual) «Mensagem do Governador de santa Catarina à Assembléia Legislativa - Florianópolis -» SC. Vol. 1 ano 2002 ,

${ }^{6}$ Estado De Santa Catarina, Secretaria do Estado e Desenvolvimento Regional, Florianópolis, 2003. (Os pontos pretos significam a implantação de Secretarias de Desenvolvimento Regional, em áreas microrregionalizadas para a institucionalização do processo de descentralização estadual).
} 
vernos locais), com objetivo de suprir as necessidades locais que o governo não consegue suprir. Sem esquecer que o governo Estadual tem suas responsabilidades em todas as áreas microrregionalizadas, bem como a presença do governo local pela municipalidade.

Lembrando que para o sistema ser efetivo ele precisa atingir seu objetivo primário de interação, considerando neste caso, a integração do planejamento com um objetivo único, o financiamento das ações básicas em níveis econômicos, sociais ambientais, tecnológicos e outros, uma vez que, a efetividade envolve medidas e resultados em relação à aplicação de uma ou a um conjunto de tecnologias no cuidado de um problema específico a exemplo do meio ambiente.

A descentralização é clara com objetivos como suprir as estruturas gerenciais, responsáveis pelo planejamento e execução das ações do governo, bem como pela articulação com as unidades representativas da região, com forças produtivas locais com a própria comunidade, no sentido de ampliar a participação da sociedade catarinense na definição de seus próprios rumos. Conta com a participação de todos os prefeitos, e vereadores e representante da sociedade civil de cada município para garantir a pluralidade partidária e a representatividade social.

Segundo MELO, 1995:98) ${ }^{7}$,’[...] uma profunda redefinição no papel do Estado vem contemplando uma agenda de reformas de inspiração neoliberal, que aponta para novas formas de resolução da crise do Estado. Deste modo busca-se minimizar a capacidade regulatória do Estado, retirar o Estado de funções produtivas e promover uma redução da estrutura administrativa. No plano das políticas públicas, ela aponta também para a descentralização e privatização de atividades sob o controle do Estado. $\mathrm{O}$ argumento centra-se no pressuposto de que a privatização determinadas áreas produziria as condições para o setor público desempenhar o que seriam as funções clássicas do Estado Mínimo; ações de estabilização econômica, administração da justiça e defesa e garantia de acesso das populações de baixa renda às ações residuais de assistência social.

Os serviços básicos da estrutura governamental estão a dois níveis: o primeiro voltado aos seguintes desenvolvimentos: econômico, geração de emprego e renda, pesqueiro, tecnológico, urbano e habitação popular, educação, cultura, saúde, esporte, bem-estar-social, saneamento básico e meio ambiente, modernização do estado e servidor público, organização do lazer e turismo, segurança pública, energia, transporte e outros; o segundo nível com visão do futuro nos

${ }^{7}$ Melo Marcus André B. C. de. (1995) «A Difusão das Reformas Neoliberais: Uma Resenha da Literatura Internacional», Política Hoje, vol. 2, nº 3, janeiro/julho. 
seguintes aspectos: melhoria da qualidade de vida, inclusão social, desenvolvimento econômico e ambiental, regionalização do desenvolvimento, modernização da gestão pública.

A proposta da descentralização do Estado compreende que o conhecimento gerado nos dois níveis mencionados se complementa num terceiro nível que é à base do conhecimento governamental, a ser implantada com os conceitos de governança eletrônica, facilitando o acesso direto, democrático e transparente da população às decisões e garantindo maior participação e agilidade dos serviços públicos.

\subsection{Microrregiões Estaduais Estabelecidas pelo Associativismo Inter- municipal}

O Estado de Santa Catarina, é constituído por 293 municípios e uma estrutura organizacional formada pelo Associativismo Intermunicipal com 21 Associações de Municípios historicamente constituídas, desde o final da década de 60, atualmente funcionamento em todo o território estadual, com um único objetivo defender os interesses institucionais dos municípios através do fortalecimento regional.

O desenvolvimento do associativismo intermunicipal no Estado Catarinense, começou no final da década de 60 com 3 unidades em funcionamento e expandiu-se em 1970, com o apoio do governo estadual na implantação das políticas de regionalização visando o planejamento e o desenvolvimento das microrregiões.

O associativismo intermunicipal se caracteriza segundo (JACOBI, 1989) pela "[...] iniciativa própria da reforma e fortalecimento da capacidade administrativa, econômica e social dos municípios". 8

Esse processo de modernização que surgiu a partir da década de 80, exigiu a criação de uma equipe multidisciplinar, para atuar em planejamento e outras atividades administrativas realizadas pelo associativismo.

A defesa institucional dos municípios consorciados e o fortalecimento regional foram os principais objetivos de planejamentos voltados às realidades de cada microrregião Com uma política de desenvolvimento econômico, social e ambiental e o uso de tecnológica adequada para soluções de seus problemas comuns.

\footnotetext{
${ }^{8}$ JacoBi, P . Movimentos Sociais e Políticas Públicas, Cortez,1989, p.89.
} 
Com a adoção do associativismo intermunicipal algumas políticas básicas de regionalização passam a ser desenvolvidas: a educação, saneamento básico, habitação, a infraestrutura, desenvolvimento econômico e social e ambiental, a agricultura familiar e outras necessidades comuns a cada nível microrregional, ou suprir aquelas áreas que se fazem descobertas pelas crises financeiras do estado, como restrição dos gastos sociais, esgotamento do estado como modelo produtor/executor, pelas mudanças no cenário internacional (globalização da economia, aumento da competição, revolução tecnológica e principalmente pela iniciativa brasileira municipal de superação do modelo de administração burocrática), na busca de melhorar a qualidade da administração pública local estrutura associativa que vem resistindo a crises socioeconômicas há 40 anos.

Para mostrar a estrutura e o funcionamento do associativismo intermunicipal tomamos a exemplo as atividades da Associação de Municípios do Oeste Catarinense, em funcionamento desde 1968, a terceira entidade do gênero a ser criada no Estado de Santa Catarina congregando os interesses dos governos locais associados.

Como entidade municipalista, mantida exclusivamente com recursos dos $\mathrm{Mu}-$ nicípios, a AMOSC de forma consorciada é um órgão prestador de serviços em projetos, consultoria e assessoramento técnico municipal. Está ao lado dos administradores públicos Municipais (Executivo e Legislativo), dando-lhes a sua contribuição efetiva para o desenvolvimento e aperfeiçoamento dos serviços prestados à comunidade.

Destacam-se dentre os principais objetivos da Associação dos Municípios do Oeste de Santa Catarina - AMOSC: defesa institucional, ampliação e fortalecimento da capacidade administrativa, econômica e social dos municípios, com a promoção da modernização administrativa municipal; mobilização para a atuação conjunta dos poderes legislativo e executivo regional; coordenação e estabelecimento conjunto de medidas e políticas públicas visando o desenvolvimento integrado da microrregião; participação em convênios e contratos de interesse dos associados; promoção de iniciativas para elevar as condições de bem estar econômico e social da comunidade; execução e elaboração de projetos, planos, programas e prestação de serviços técnicos especializados; cooperação intermunicipal e intergovernamental, com ações de colaboração na divulgação das normas e exigências técnicas e legais dos órgãos públicos e instituições de assistência técnica e financeira aos Municípios associados; reivindicação e gestão de recursos técnicos e financeiros do Estado e da União, mediante acordos, convênios ou contratos; reivindicação para a descentralização de serviços públicos estaduais e federais, de interesse dos municípios associados; estímulo e promoção do intercâmbio técnico-administrativo; elaboração, proposição de estudos e levantamentos sócio-econômicos e políticos regionais. 
Segundo (RANNEY, 1997) [..] políticas públicas constituem, de modo amplo, um processo definido de alocação de recursos para a sociedade a partir de decisões autorizadas ou sancionadas por atores governamentais. As políticas públicas surgem a partir de uma ação intencional de agentes, indivíduos grupos, organizações, instituições e governo para tender racionalmente a determinados interesses. $^{9}$

A defesa institucional dos Municípios consorciados e o fortalecimento regional foram pontos marcantes do início do associativismo municipal que compreendeu o período de 1968 a 1976, quando estiveram presentes e resultaram das reivindicações das assembléias da entidade: a obras como a implantação BR 282 no oeste catarinense; a implantação de meios de comunicações interligados com a capital do Estado; o fortalecimento e manutenção por um período da Secretaria dos Negócios do Oeste; a implantação e melhorias do Aeroporto Regional de Chapecó; o apoio para a implantação e transformação da Fundação de Ensino e Desenvolvimento do Oeste - Fundeste em Universidade Comunitária de Chapecó - Unochapecó.

A AMOSC- teve seu primeiro plano de desenvolvimento regional estruturado em agosto de 1969, após dois um ano de sua fundação resultado do convênio da AMOSC com SUDESUL - Serviço de Desenvolvimento do Sul (órgão federal). Foi a primeira e grande experiência transmunicipal, fundamentada na formulação de políticas de desenvolvimento econômico e social, com implantação de infra-estrutura física e para integração da região ao contexto catarinense e brasileiro de forma articulada com o plano Nacional de Desenvolvimento PND concebido pelo governo federal.

A AMOSC passou a voltar-se a partir de 1977 à prestação de serviços técnicos especializados, com a organização de uma estrutura técnica visando a elaboração de mais de 3.000 Projetos de obras públicas, nas áreas de Arquitetura, Engenharia, Agrimensura e Planejamento Urbano, durante os vinte e dois anos de atuação nestas áreas. Participou também através dos seus Prefeitos, Vereadores e técnicos da mobilização para a Reforma Tributária, Emenda Constitucional Passos Porto em 1985 e Reforma Constitucional de 1988, que resultou em consideráveis ganhos de receitas aos municípios brasileiros. Em 1987 implantou, junto aos Municípios consorciados, um projeto arrojado e inovador no âmbito do Estado de Santa Catarina, de informatização dos municípios, com a realização de um Plano Diretor de Informática, estruturação de equipes de desenvol-

\footnotetext{
${ }^{9}$ Ranney, Austin (1993), Political Science and Public Polici. Chicago, Kmarkhan Polishing Company. In, SouzA. A . T. M. «Argumentos em Torno de Um velho "Tema" A descentralização», Dados , vol40, n. ${ }^{\circ}$ 3, Rio de Janeiro, 1997.
} 
vimento de sistemas, processamento de dados através das Prefeituras Municipais e implantação de uma rede de microcomputadores interligados à associação.

Um terceiro e marcante período que consolidou a entidade e sua importância regional teve início em 1993, passou a executar simultaneamente dois grandes projetos de repercussão regional e que visaram melhorias na eficiência administrativa das administrações municipais e o desenvolvimento regional integrado. Foram realizados a partir deste período o Programa de Modernização Administrativa da Associação e dos Municípios consorciados e o Plano Básico de Desenvolvimento Econômico e Ecológico.

Com estes dois instrumentos de planejamento, a entidade passou a atuar intensivamente em outras áreas de suporte aos municípios, entre elas a educação, saúde, serviço e assistência social, propostas de desenvolvimento das atividades econômicas urbanas e rurais voltadas a geração de emprego e renda nos setores primário, secundário e terciário

Aqui, o conceito de planejamento, integração e desenvolvimento regional emergiram das teorias administrativas, econômicas e sociológicas para a prática cotidiana dos municípios.

Múltiplas foram às frentes de atuação desde sua origem: reivindicar obras e programas de amplitude regional, defender os interesses comuns da microrregião, qualificar os servidores públicos municipais nas áreas estratégicas, prestar serviços técnicos de média e alta complexidade. Atendendo atualmente a 20 municipalidades que juntas, ocupam território de 2.955 quilômetros quadrados e abrigam 247.128 pessoas. Sendo que as demais microrregiões do Oeste catarinense estão cobertas por associações de municípios que surgiram a partir da AMOSC, e que hoje trabalham em consenso pelos interesses regionais.

O fortalecimento desta entidade e o aumento das áreas e subáreas de sua atuação exigiram a construção de uma sede física, inaugurada em agosto de 1973. Foi a primeira Associação de Municípios do Brasil a possuir sede própria, ampliada em 1987 e atualmente com espaço físico de $744 \mathrm{~m}^{2}$.

O aumento das demandas sociais e a modernização dos três níveis da Administração pública transformaram o processo de gestão das cidades e dos municípios em uma atividade de alta complexidade e relevância. Para assessorar adequadamente os Prefeitos e Vereadores, a AMOSC criou na década de 1970 um quadro técnico permanente especializado, paulatinamente ampliado e que ordenadamente atende as áreas de administração, recursos humanos, finanças públicas, tributação, assessoria jurídica, informática, saúde e serviço social, educa- 
ção, engenharia civil, agrimensura e cartografia, arquitetura e planejamento urbano, planejamento regional, engenharia química e nutrição.

O compromisso de elevar o nível de eficiência das administrações locais foi perseguido tenazmente. Em 1994, através de convênio de cooperação técnica com o Governo do Estado, a AMOSC elaborou diagnósticos administrativos de todos os municípios. Em conseqüência desse trabalho, implantou o projeto de modernização administrativa e criou uma equipe multidisciplinar permanente para implementá-lo.

Os efeitos foram percebidos em mudanças comportamentais junto aos servidores públicos municipais, em favor de uma visão de racionalidade nos serviços e eficiência nos controles internos. O programa oportunizou manuais de rotinas e procedimentos nas áreas essenciais da gestão municipal, como recursos humanos e assistência social.

Modernização conceitual, metodológica e tecnológica é diretriz permanente na AMOSC. Em 1988, ao completar 20 anos de fundação, entrou em funcionamento o moderno Centro de Processamento de Dados. O CPD permitiu desenvolver e colocar a disposição dos municípios os sistemas de contabilidade geral pública, tributos, folha de pessoal, controle patrimonial, controle de produção agropecuária e outros aplicativos utilizados pelos municípios consorciados.

Os recursos de informática e do processamento eletrônico de dados também conferiram maior agilidade e precisão aos setores de engenharia civil, agrimensura, arquitetura e de controle interno da associação e das prefeituras municipais, ampliando a eficiência dos serviços prestados à comunidade.

A vocação para o planejamento e o desenvolvimento regional foi renovada em julho de 1992, quando a Assembléia Geral aprovou a realização do Plano Básico De Desenvolvimento Regional (PBDR) em convênio com o Governo do Estado. O projeto exigiu três anos de pesquisas, análises e estudos; foi apresentado à comunidade em agosto de 1995 e uma de suas propostas corporificou-se no Fórum de Desenvolvimento Regional Integrado (FDRI).

A proposta foi amadurecida em viagem de estudos que, em setembro de 1995, prefeitos, vice-prefeitos, vereadores e técnicos da região empreenderam à Holanda, França, Alemanha e Itália. Um dos resultados dessa missão ao exterior foi à contratação da Sociedade de Estudos Econômicos Nomisma, ligada a Universidade de Bologna, na Itália, para cooperar com a AMOSC na definição de um novo modelo regional de desenvolvimento. No mesmo período, a microrregião foi selecionada pela Secretaria de Desenvolvimento Econômico e Integra- 
ção ao Mercosul para sediar o primeiro projeto piloto para o desenvolvimento integrado do Oeste.

Culminando com todas essas tratativas, a assembléia geral da AMOSC aprovou em janeiro de 1996 a criação do Fórum de Desenvolvimento Regional Integrado (FDRI), um órgão colegiado interinstitucional e multidisciplinar destinado a discutir e propor soluções para as grandes questões microrregionais.

Assinalando uma nova fase de cooperação transmunicipal, os prefeitos deliberaram em julho de 1996 pela criação do Consórcio Intermunicipal de Saúde, o Cis AMOSC. Um dos primeiros do gênero no país, o CIS AMOSC assegura assistência médica especializada, mediante consultas e exames de média e alta complexidade, aquisição de materiais e equipamentos de saúde, proporcionando à população dos municípios consorciados o atendimento geralmente não disponível no sistema público.

Em novembro de 1998 surge o SAGA - Instituto de Desenvolvimento Regional - com o objetivo de ser o órgão operacionalizador dos projetos e ações que promovam o crescimento integrado na região. Ao lado do Fórum de Desenvolvimento Regional Integrado, do CIS AMOSC e do Cidema, o Saga torna-se mais uma estrutura vinculada à Associação dos Municípios do Oeste de Santa Catarina.

O Instituto incentiva, participa e contribuem para o desenvolvimento de atividades econômicas, financeiras, técnico-científicas, agropecuárias e agroindustriais. Favorece a realização de atividades econômicas em associação com os diversos organismos e instituições nacionais e internacionais, visando a promoção dos serviços de assistência técnica, desenvolvimento da pesquisa científica e tecnológica, estudos de viabilidade

Em julho de 1999 foi criada uma nova entidade de atuação microrregional, o Consórcio Intermunicipal de Desenvolvimento Econômico e Meio Ambiente, CIDEMA. O Consórcio tem, entre seus objetivos, planejar, adotar e executar planos, programas e projetos destinados à recuperação, conservação e preservação do meio ambiente do território dos Municípios consorciados. Está entre as prioridades do Cidema desenvolver programas e adotar medidas destinadas à recuperação e preservação das fontes de abastecimento de água, do tratamento e destinação do lixo. O Consórcio também atua nas áreas do turismo, lazer, qualificação, valorização e incremento de potencialidades, oportunidades e produtos locais e regionais, orienta as empresas para o crescimento do valor agregado e do resultado econômico nos Municípios e microrregião.

O CIDEMA desenvolve seis programas exitosos: Pro-água, Coopercasa, Proale, Pró-Notas, Pró-Cidades, Iberê. 
O Programa Pro-água controla a qualidade da água de consumo no município com assessoria na proteção e manutenção de fontes, poços, redes adutoras e de distribuição de água e treinamento dos operadores dos sistemas de fornecimento de água, realiza o levantamento das fontes e poços existentes, locando-os nos mapas municipais, permitindo o conhecimento da situação atual e planejamento das futuras ampliações.

O Programa Coopercasa foi criado com o intuito de promover o desenvolvimento rural através da industrialização associada. O Programa de Alimentação Municipal (Proale) criado em março de 2001 atende os municípios assessorando o Programa de Merenda Escolar com elaboração de cardápios, privilegiando os produtos regionais, educação alimentar e capacitação dos servidores.

O Programa Pró-Notas incentiva à emissão de Nota Fiscal através da campanha Nota Premiada que distribui prêmios para incrementar a arrecadação de impostos.

O Programa Pró-Cidades busca dotar os municípios de Plano Diretor visando promover o pleno desenvolvimento das funções sociais da cidade e da propriedade urbana, garantindo o bem estar dos habitantes. O Programa Iberê promove o gerenciamento ambiental ao nível de microbacias hidrográficas.

Para gerir e operar a estrutura municipalista polarizada na AMOSC, a Associação investe em recursos humanos. Para capacitar, atualizar e reciclar os servidores públicos ao exercício das atividades cada vez mais complexas da esfera municipal, a AMOSC promove, anualmente, ciclos de estudos que representam dezenas de cursos de alto nível e permitem requalificar centenas de funcionários. Os cursos abrangem todas as áreas da administração municipal e reflete direta ou indiretamente na melhoria dos serviços prestados à população. Especialistas com amplo conhecimento nos temas pautados e técnicos da AMOSC ministram as aulas, garantindo assim o sucesso dessa iniciativa.

Uma das mais importantes e inovadoras atividades que a AMOSC vem prestando nos últimos anos é a implantação de bases cartográficas por meio de GPS (Sistema de Posicionamento Global) para a elaboração dos mapas rodoviários digitais. O uso de recursos de cartografia regional permite a confecção de mapas com informações geográficas atuais e complementares, mediante obtenção de dados por diferentes sensores e mapeamento sistemático produzido com auxílio de sistemas de processamento de imagens e de informação cartográfica. Essa tecnologia cartográfica, associada a imagens de satélites, imagens de radar e fotografias aéreas, permitirá a AMOSC oferecer no futuro às Prefeituras produtos cartográficos como mapas de bacias hidrográficas, mapas rodoviários, mapas altimétricos, mapas ambientais, mapas de uso e ocupação do solo, mapas 
temáticos, conforme a necessidade do usuário; mapas para confecção de planos diretores e implantação de marcos geodésicos e marcos de divisas municipais.

Manifestação inequívoca de sua influência em nível sulbrasileiro, a AMOSC participou de forma atuante e decisiva da implantação do programa da Mesorregião Grande Fronteira do Mercosul. Trata-se da mais arrojada experiência de planejamento e desenvolvimento regional, envolvendo 130 municípios catarinenses, 238 sul-rio-grandenses e 47 paranaenses. O SAGA, uma das Instituições executoras deste Programa do Ministério da Integração Nacional e tem representante no Fórum Mesorregional.

A criação da Mesorregião originou-se da elaboração, em 1997, do Plano de Desenvolvimento Sustentável da Bacia do Rio Uruguai, apresentado pelo Ministério do Planejamento e Orçamento. Tem como objetivos definir diretrizes, estratégias e prioridades para o desenvolvimento da área de acordo com sua realidade, limites e potencialidades, orientados para sua inserção competitiva no mercado local, regional, nacional e global e, principalmente, para uma integração intra e inter-regional sustentável.

Sua missão - prestar assessoramento técnico e institucional visando a excelência da administração pública municipal e o desenvolvimento regional sustentado - é reafirmada cotidianamente em centenas de ações que ampliam e fortalecem a capacidade administrativa, econômica e social dos municípios através da assistência técnica e do planejamento local e regional.

Com a implantação do processo de descentralização e desconcentração administrativa iniciada em 2000 as Associações de Municípios e a Federação Catarinense de Municípios - FECAM, manifestaram as lideranças políticas a preocupação em relação à área de abrangência das Secretarias de Desenvolvimento Regional, pois não coincidiam com as das associações. Para citar como exemplo, na microrregião da AMOSC composto por 20 municípios temos a seguinte configuração: Secretaria de Desenvolvimento Regional - Chapecó 11 municípios; SDR São Lourenço do Oeste 6 municípios; SDR Palmitos 2 municípios e SDR Maravilha 1 município. A não ser este reparo, estamos participando ativamente de projetos e ações das SDR, seja no atendimento pontual para a elaboração de projetos, ações conjuntas de capacitação e organização de seminários, também a participação nas Câmaras Temáticas. A proposta da descentralização vem de encontro ao que a AMOSC já pratica como ação definida na sua missão de atuar no planejamento e desenvolvimento regionais de longa data, e mais efetivamente a partir de 1993 com o Plano Básico de Desenvolvimento Regional e a criação do Fórum de Desenvolvimento Regional Integrado, contemplando mais de cem entidades, com a participação do Poder Público (Executivo e Legislativo) e Sociedade Civil. No mérito entendemos que a região será benefi- 
ciada com investimentos e ações efetivas. O Governo do Estado mais presente nos municípios e menos litoralizado e a aplicação dos recursos públicos de forma mais pulverizada. É nesta linha de pensamento que entendemos não haver conflito, pois também defendemos que o desenvolvimento deve ser integrado e equilibrado, ações efetivas que possam fixar as pessoas nos pequenos municípios evitando desta forma a aglomeração urbana em alguns centros maiores

\section{CONCLUSÃO.}

Conclui-se que tanto o processo de descentralização do Governo do Estado Catarinense como as estruturas do Associativismo Intermunicipais possuem programas com montagens organizacionais e administrativas complexas e cujos objetivos são implementados e executados e direcionados para o desenvolvimento microrregionalizado. Para o Estado a descentralização significa a redefinição de novos níveis de intervenção política. Para os Governos Locais, o associativismo, não está sob o jugo nem de partidos, nem de mercados, nem do Estado, é um quarto poder, constituído, reconhecido e independente, que está totalmente voltado aos interesses municipais.

Porém, a presença do Estado pela descentralização e dos Governos Locais pelo associativismo, ambos com divisões microrregionais estabelecidas, no mesmo terreno, sobrepostas, planejamentos distintos, atividades diferenciadas para as mesmas demandas, com objetivos fins e situações financeiras diferenciadas, mas com graus de maior e menor estabilidade social, traz ao governo estadual um desperdício de recursos, entende-se que segundo o papel do estado contemporâneo é de delegação de poder e não de competitividade.

Assim sendo, a descentralização enfrenta dificuldades de identificação, mesmo com áreas definidas e dependência de plano de governamental, já o associativismo, além de ser histórico na formação das suas comunidades possui uma certa estabilidade frente a estas. O que se deve entender são as inter-relações estratégicas e importantes entre as duas organizações nos fatores; político, econômico, social e ambiental e tecnológico. E neste processo como identificar a avaliação comparativa da efetividade na descentralização. Segundo (TIROLE, 1990 e 1994), "[...] aponta que a desejabilidade e força de incentivos ao desempenho tornam-se mais acentuadas, aumentando a efetividade e a eficácia de mecanismos formais de incentivo, aprimorando conclusões sobre a eficiência dos agentes ${ }^{\text {“10. }}$.

\footnotetext{
${ }^{10}$ Tirole, J . The THEORY of industrial Organization. Cambridge. MA. The MIT PRESS,1990., in Homo Page: http://w.w.w.Ipea.gov.br
} 


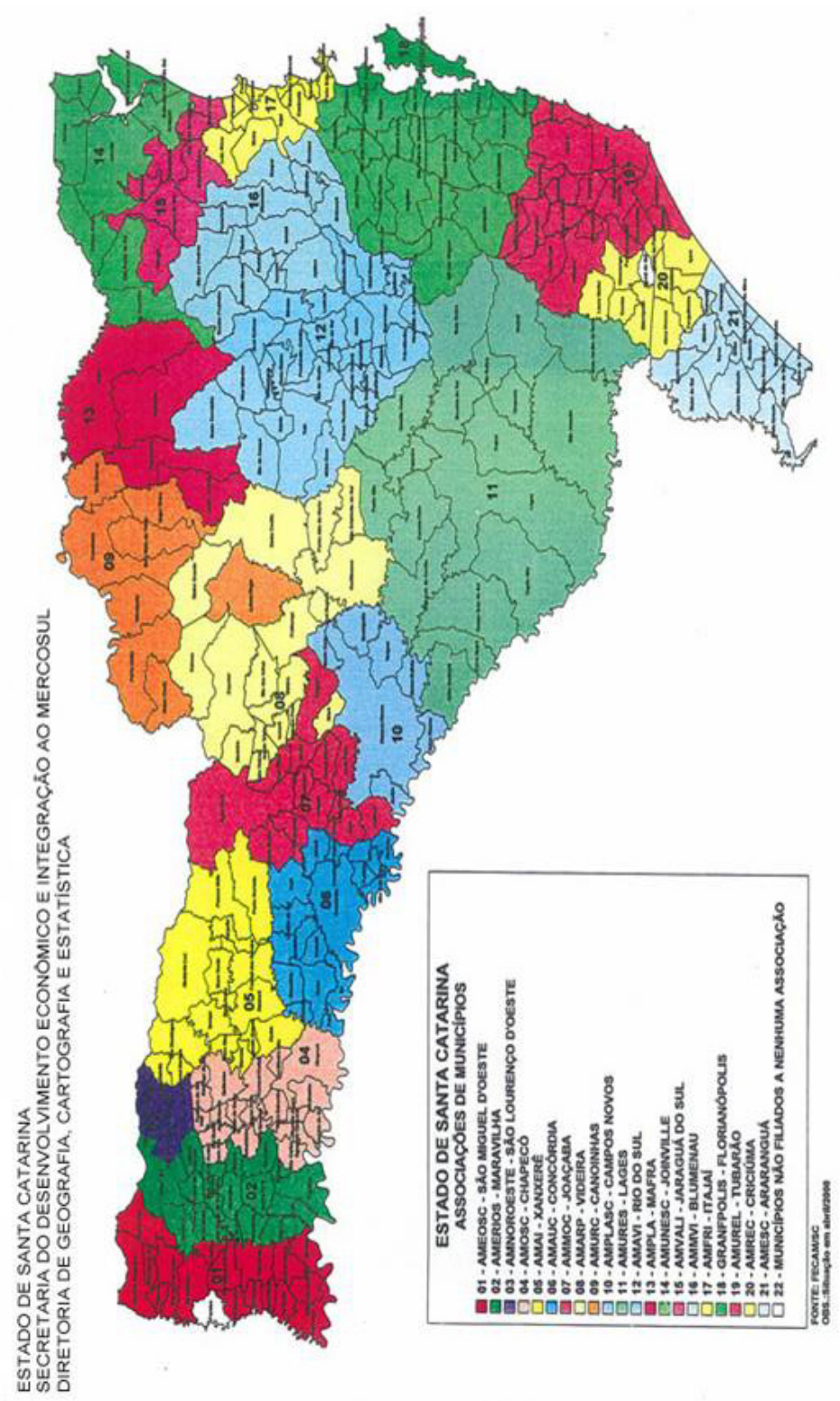

Fig. $2^{11}$

${ }^{11}$ Estado De SANTA CATARINA, Microrregiões estaduais implantadas pelo Associativismo Intermunicipal, Secretaria do Desenvolvimento Econômico e Integração ao Mercosul Diretoria de Geografia, cartografia e estatística, Florianópolis , 2000. 
Embora é visível a necessidade de integração entre ambos para melhorar a efetividade dos resultados. Como a exemplo dos setores responsáveis pela descentralização; no implemento de um projeto social enfatizam a participação, já no associativismo como as características participação estão presentes, preocupa-se na valorização da cidadania através da cultura, na capacitação profissional, no entanto, para o financiador, seja ele, de ordem pública ou privada, nacional ou internacional, é importante o conhecimento sobre a eficácia e a efetividade dos resultados.

Como as ações se tornam cada vez mais complexas explicitar as diferentes visões e expectativas dos atores envolvidos não é uma tarefa fácil, a efetividade é a incorporação das mudanças que podem ocorrer pela implantação de determinado programa na realidade da população alvo, diferente do impacto que corresponde ao grau de influência e de expansão de um projeto realizado.

O Critério da efetividade é orientado para as ações futuras, como nas duas organizações existe escassez de recursos a integração de ambos seria essencial para o desenvolvimento ser efetivo e para obter maior aproveitamento de recursos. Analisando o associativismo e a descentralização a última contribui para a liberação do poder econômico. Os municípios posicionam-se como receptores democráticos, de maneira a desempenhar consenso e justiça na implantação de programas básicos que asseguram o desenvolvimento local e o Estado perde a oportunidade de delegar.

Para DAWBOR (1994) $)^{12}$, “[...] a descentralização constitui uma questão de sobrevivência sócio-econômica dos países subdesenvolvidos, mas, além disso, pode desenvolver ao cidadão um espaço onde ele possa contribuir na construção de sua cidadania e da ampliação dos espaços sociais".

O objetivo posposto pela descentralização norteia melhorias na qualidade da gestão a nível local. Neste processo, na prática a interação entre as duas formas administrativas deveriam se complementar e incorporar os serviços das estruturas microrregionais formadas pelos municípios para desenvolvimento local com forte impacto para o desenvolvimento Estadual e Nacional. Entretanto somente a atuação positiva dos governantes fará aumentar as capacidades e recursos dos setores marginalizados, para que estes, tenham menos desvantajosas em suas atividades. Valorizando a ação do Estado e reconhecendo nele a competência para gerar as próprias condições para a auto-organização da sociedade na formação do capital social, consideramos, a falta de esclarecimento a população do

12 . DAwBOR, Ladislau. A reprodução social: proposta de uma gestão descentralizada. Petrópolis, R.J. Vozes, 1994; p. 95. 
que consiste o processo de descentralização instituído, e deve-se a falta de conhecimento popular do que compete a um processo de descentralização.

Como dedução entendemos que os mecanismos existentes são insuficientes para a efetividade da descentralização, que esta desafia os modelos tradicionais de intervenção e reivindicam novas lógicas e novos parâmetros para sua concepção descentralizada, intersetoriais, fundadas no território e enraizadas na participação cidadã, de forma a reconhecer e assumir os sujeitos como na condição de protagonista. A intenção é justamente acentuar a relevância das ações políticas positivas na direção da descentralização de forma a possibilitar a efetivação.

Como termino gostaríamos de salientar que a reforma do Estado, no sentido descentralizador carece de instrumentos básicos para sua efetivação. Em um momento em que se fala da descentralização e da valorização das forças locais se torna evidente a incapacidade dos municípios e das cidades brasileiras para assumir as diversas responsabilidades sem orçamento próprio como prevê o processo de descentralização.

Para a realidade brasileira a descentralização é vista pela população apenas como mais um ato governamental. A população continua dependendo de seus governantes para lhes solucionar problemas básicos. Porém, não quer dizer que, a efetividade da descentralização aos olhos de estudos científicos não venha se efetivar, porém, em longo prazo. Para (DAWBOR, 1994), [...] as organizações são efetivas quando seus critérios decisórios e suas realizações apontam para a permanência, estruturam objetivos verdadeiros e constroem regras de conduta confiáveis e dotadas de credibilidade para quem integra a organização e para seu ambiente de atuação"13.

${ }^{13}$ DAwBor, Ladislau. A reprodução social: proposta de uma gestão descentralizada. Petrópolis, R.J. Vozes, 1994; p. 95. 